\title{
DIE KONINGSBEDE AS ELEMENT IN DIE KRONINGSRITUEEL.
}

By vergelyking van I Kon. 3:4-15 met II Kron. 1:1-13 kom al gou aan die lig, dat terwyl die twee skrywers dieselfde geskiedenis behandel, daar so groot afwykings onderling bestaan, dat dit nie moontlik is om die verhaal van Kon. as 'n regstreekse bron vir die Kronis te beskou nie. Hier, sowel as op ander plekke is dit nodig om tussen die Kronis en Konings 'n tussenstadium aan te neem, die sogenaamde "Uitleg van die boek van die konings", wat uitdruklik gesiteer word in II Kron. 24:27. Aangesien hierdie werk vermoedelik die bron vir die meeste geskiedenisse van Kronieke is wat in Konings nie of in afwykende vorm vertel word, moet ons anneem dat hierdie „Uitleg. meer was as net 'n kommentaar op die boeke van die Konings; dit het oorlewerings opgeneem, wat in Kon. nie voorkom nie, en het in party gevalle dieselfde gebeurtenisse in afwykende bewoordings verhaal.

As dit so is, dan kan ons die verhaal van die Kronis omtrent die droom van Salomo te Gibeon as meer beskou as net 'n afwykende resensie of nadere bewerking van die ooreenkomstige verhaal by Konings; dit verwerk ' $n$ eie vorm van die oorlewering. Hoewel die Koningsverhaal in sy teenwoordige vorm seker een en 'n halwe eeu ouer is as dié wat ons in Kron. vind, bestaan tog die moontlikheid dat in Kron. trekke bewaar is, wat ons dig by die historiese waarheid bring.

Sulk ' $n$ trek is die voorstelling in Kron., dat Salomo se offer in Gibeon die amptelike begin van sy regering was. By Kron. volg onmiddellik op die afsluiting van die beskrywing van Dawid se regering die tog van Salomo na Gibeon; in Kon. volg na Dawid se dood eers die afrekening van Salomo met sy teenstanders, wat tenminste drie jaar vat ( 1 Kon. 2:39), en sy huwelik met die dogter van Farao ( 1 Kon. $3: 1$ ). Hoewel dit hier en elders duidelik is dat die skrywer van Konings nie na 'n chronologiese volgorde gestreef het nie, is die resultaat van die plaatsing van die Gibeon-episode agter die genoemde geskiedenisse tog, dat die leser nie die indruk kry, dat Salomo se besoek aan Gibeon saamhang met sy troonsbestyging nie.

In Kronieke is daardie samehang egter onmiskenbaar aanwesig. Dit blyk alreeds uit die feit, dat die Gibeon-episode begin met die woord „En Salomo, die seun van Dawid, het hom versterk in sy koningskap" en eindig met die sinnetjie ,en hy het oor Israel geregeer" (beter : „en hy het sy regering oor Israel begin"). In die eerste vers kom bedektelik tot uiting, dat die oorgang van die regering van Dawid op Salomo in krisis was; in die laaste vers word aangedui, dat hierdie krisis oorwin is, en Salomo algemeen as koning erken. Daartussen lê die Godsverskyning in Gibeon. 
In verband daarmee is ook die voorstelling van die Kronis, dat Salomo in geselskap van die verteenwoordigers van geheel Israel na Gibeon gegaan het 'n welkome aanvulling van Kon., waar ons niks van die begeleiders van die koning hoor nie. Die offerfees te Gibeon was 'n plegtigheid, waaraan geheel Israel deelgeneem het. Die duisend "brandoffers" wat sowel Kon. as Kron. vermeld, sal wel opgevat moet word as "brandoffers en dankoffers", sodat daar vir die aanwesiges "n groot feesmaaltyd aangerig is, vgl. I Kon. 3:15. 'n Sodanige maaltyd verbind vors en onderdaan tot wederkerige trou, vgl. II Sam. $3: 20$; I Kron. 12:39.

Vermoedelik moet ons daarom die gebeurtenisse van I Kon. 1 en 2 opvat as die stryd om die opvolging van Dawid as koning van Jerusalem, terwyl die tog na Gibeon in verband staan met die koningskap oor Israel, wat as sodanig nie an die heerskappy oor Jerusalem verbind is nie. Die vraag kan selfs opkom, of Salomo te Gibeon koning oor heel Israel geword het of wel oor die konfederasie wat in Benjamin sy sentrum gevind het, die ou koninkryk van Saul. Miskien moet ons daarnaas reken met 'n dergelike plegtigheid te Hebron, waar hom die koningskap oor Juda toegeken is ${ }^{1}$ ) en een of meer ander byeenkomste in die noordelike heiligdommen soos Sigem, die Tabor en Dan. Die koning moet ..verskyn" aan die stamme, en deur die godheid as koning erken word, voor hy wettig koning is.

Salomo se offerfees in Gibeon is dus 'n episode uit sy tog langs die heiligdomme, en die beskrywing van sy ondervindings te Gibeon bevat trekke wat tiperend is vir die gang van die kroningsritueel. In die besonder dink ons hier aan die bekende beskrywing van Salomo se bede. Nadat die offer gebring is, lê die koning homself te slape in die heiligdom, vgl. Gen. 28:11, kennelik met die bedoeling om 'n droomorakel te ontvang. Dit gebeur dan ook, altans volgens die teks in Kon.; volgens die Kronis gebeur meer: God self verskyn aan Salomo. Die direkte openbaring geld as hoër onderskeiding as die droomorakel, vgl. Num. 12:6-8. Die inhoud van die godsopenbaring lyk baie gering: voorlopig kom dit neer op die ene sinnetjie: „Begeer wat Ek jou moet gee."

Egter is hierdie kort woord vol betekenis. In die eerste plek is dit ' $n$ terugslag op die gawes wat die koning op die altaar gebring het; die Godheid toon dat Hy die offers aanvaar het, met ander woorde dat Hy Salomo in sy gemeenskap opgeneem het. Daardie gemeenskap is egter nie volkome nie, solank as die Godheid van sy kant nou ook nie 'n geskenk aan Salomo gegee het nie. Ons het hier dus 'n geval van die oue reël do ut des, „Ek gee sodat jy (vir my iets in ruil) mag gee." Hierdie reël is in die verlede dikwels veel te nugter as in soort

1) Volgens Flavius Josefus, Antiquitates VIII, 2, speel die geskiedenis van I Kon. 3 hom af te Hebron. 
ruilhandel tussen die mens en die Godheid geïnterpreteer. Sinds die studies van LeVy BrüHL oor die Mentalité primitive weet ons egter, dat die gee van 'n geskenk die gemeenskap tussen twee persone tot stand bring; as iemand iets gee, dra hy daarmee ' $n$ deel van sy eie persoonlikheid aan die ander oor. Die wisseling van geskenke is 'n onderlinge verbond; van daardie oomblik af is die een verantwoordelik vir die ander. Wanneer dus die Godheid vir Salomo aanbied, van sy kant ook iets aan die koning te gee, dan word daarmee aangedui, dat God met die koning in ' $n$ verbond tree, waarvan die geskenk die teken en onderpand is.

Ons kontensie is nou, dat wat in I Kon. 3 en II Kron. 1 verhaal word as 'n gebeurtenis wat eenmaal met Salomo plaas gevind het, 'n vaste element in die kroningsritueel van Gibeon, wellig ook van ander heiligdomme, gevorm het. Die koning bring sy offerandes, en daarop antwoord die Godheid met die uitnodiging dat die koning nou sy wens mag uitspreek. Gewoonlik sal die priester in die ritueel die rol van die godheid vervul het; as dit in die verhaal wat ons tot nou toe besig hou anders gaan, dan is dit 'n stuk prediking van die Bybelskrywers: wat anders net skaduwee en simboliese handeling was, word ten aansien van die Messiaanse koning werklikheid. God spreek regstreeks, sonder bemiddeling van priesters, tot sy verkorene.

Die formule waarin die Godheid sy uitnodiging klee, is kort soos dit in 'n orakel verwag kan word: „Begeer wat Ek jou moet gee." So altans vertaal die Afrikaanse Bybelvertolkers, op die voetspoor van die Reformatoriese vertalings. Ook J. GoeTtSBERGER in sy kommentaar op Kron. (1939) doen dit nog. Die meeste nuwere vertalings, reeds van KEIL se Konings-kommentaar (1872) af, vat dit as twee selfstandige sinnetjies op: „Vra! Wat moet Ek jou gee?" Die Septuaginta op Kron. laat altwee die interpretasies toe; dié op Kon. het 'n variant, wat waarskynlik nie sonder betekenis is nie! „Doen vir jouself 'n versoek!" (aitèsai ti aitèma sautooi). Ons kom daar later nog op terug.

Wanneer ons die uitnodiging van die kant van die Godheid so in twee sinnetjies splits, dan sien ons dat dit moontlik is dat die Godsopenbaring nog korter kan wees as wat ons eers gedink het; dit sou ook kan bestaan in die enkele woord „Vra!" Juis in hierdie vorm is dit 'n goeie antwoord op die offerande, want dit is in wese niks anders as die inleiding op die versoek wat die koning gaan doen. Die verlof om daardie versoek te mag doen word toegestaan met hierdie woord.

Die inhoud van die versoek, waartoe op hierdie manier verlof gegee is, kan baie verskillend wees. I Kon. 3:11 som 'n paar moontlikhede op: ' $n$ lang lewe of rykdom of die dood van die vyande; Kron. voeg daar nog aan toe: skatte en eer. IDit word in Salomo geprys. dat hy 'n meer innerlike saak begeer het; volgens Kronieke wysheid 
en kennis, om hom bekwaam te maak tot die koningstaak in 'die algemeen; volgens Konings ,'n opmerksame hart", spesiaal met die oog op die regspraak, wat egter 'n paar verse verder beskrywe word as ,' $n$ wyse en verstandige hart". Hierdie keuse het natuurlik ook betekenis vir die volk, aan wie die gesprek tussen koning en Godheid bekend gemaak is : daarmee is ' $n$ vredeliewende regeringsprogram aangekondig en die koning as die beskermer van die reg by sy onderdane aanbeveel.

Op die vraag, in hoeverre Salomo aan hierdie programma trou gebly het, gaan ons hier nie in nie. Vir ons doel is dit voldoende as ons die samehang tussen koningsoffer, uitnodiging van die Godheid tot die uitspreek van ' $n$ wens, en die daaropvolgende wens van die nuwe koning onderken het.

Die vraag kom op, of ons by ander geleenthede in Israel dieselfde seremonie kan waarneem.

Ongelukkig word nêrens in die Ou Testament 'n volledige beskrywing gegee van die ingewikkelde stelsel van rites wat die kroning van 'n nuwe koning begelei het. Die meeste gevalle dat 'n nuwe koning gekroon word is so kort beskrywe, dat ons daar geen bevestiging van ons vermoede aangaande die dialoog tussen koning en godheid kan verwag nie.

Egter is daar ' $n$ paar passasies uit die Psalms, wat in dieselfde rigting wys. Dis juis daar dat ons telkens gegewens vind betreffende die tempeldiens, wat ons in die wet en historiese boeke tevergeefs soek. Ons sal hulle in die volgorde van die Psalmboek bespreek.

Die eerste teks wat ons aandag vra is Ps. 2:8: „Eis van My, en Ek wil nasies gee as $u$ erfdeel en die eindes van die aarde as $u$ besitting." In afwyking met vroeëre opvattings ('n kort en leerryke oorsig daarvan in F. M. TH. BöHL, Psalmen, Tekst en Uitleg, I, p. 98-100) word gewoonlik teenwoordig aangeneem, dat Psalm 2 'n liturgie by 'n kroningsfees is. Meer as tot nou toe gedoen is, sal ons onderskeid moet maak tussen die jaarlikse herfsfees, waarby die Godheid, en eventueel ook die aardse koning, opnuut sy troon bestyg, en die seremonie wat 'n koning maar net eenmaal kan vier, sy kroningsfees. Tot daardie laaste reken ons liturgieë soos hierdie psalm en Ps. 45.

Die offers wat aan die dialoog tussen koning en Godheid voorafgaan word in ons psalm nie vermeld nie. Maar die woorde „Eis van my" is onmiskenbaar, veral as mens bedink dat hier in die Hebreeus dieselfde werkwoord sjă'al gebruik is as in I Kon. 3:5 en II Kron. 1:7. Wat die rede is, waarom die Afrikaanse vertalers hier 'n ander woord gebruik het as in Kon. en Kron., bly onduidelik; die werkwoord sjă'al word op sestien verskillende maniere deur hulle weergegee.

Die inhoud van die koningsbede, waarop Ps. 2:8 sinspeel is die opperheerskappy oor die omwonende volke. Ons moet waarskynlik 
dink aan die skatpligtige nasies soos die Edomiete, Moabiete en derglike meer. By die dood van die ou koning, aan wie hulle trou gesweer het en wat hulle ontsag ingeboesem het, meen hulle dat hulle 'n kans het om die susereiniteit van Israel se koning af te werp; as antwoord op die bede van die koning verkondig nou die Godspraak dat die jong koning sy gesag oor hierdie volke met $\mathrm{krag}$ sal handhaaf. Dit is ' $\mathrm{n}$ bede en ' $n$ belofte, wat geen plek sou kan hê in Gibeon of 'n lander stamheiligdom van Israel nie; dit is net in die persoonlike heiligdom van die Dawidiese dinastie op sy plek, want alleen daar kan oor die heerskappy oor nie-Israelitiese volke gepraat word: dis feitlik nie Israel wat oor Edom heers nie, maar Dawid of Salomo, wat toevallig ook koning oor Israel is. Edom of Ammon is nooit geannekseer nie, maar die koning van Israel het koning ook oor hierdie lande geword, vgl. II Sam. 12:30, of wel as "opperkoning" gegeld, vgl. I Kon. 4:21 met II Kron. $9: 26$.

So is dit verklaarbaar waarom die heerskappy oor ander volke nie in I Kon. 3 of II Kron. 1 as moontlike inhoud van die koningsbede te Gibeon vermeld word, terwyl ons dit in ons psalm, wat uit die Jerusalemse heiligdom stam, wel aantref. Verder moet ons nog opmerk dat die woorde "Eis van My" in die Hebreeus uit die gewone ritme van hierdie psalm uitval; dit is in hierdie geval geen rede om hulle te skrap nie (vgl. in BuHL, KITTEL ${ }^{3}$ ) maar 'n bewys van die liturgiese karakter van hierdie uitdrukking: dikwels kan mens opmerk dat liturgiese wendings buitekant die gewone metrum van die psalms val.

' $n$ Tweede sinspeling op die koningsbede kan gevind word in Ps. 20. Die Afrikaanse vertaling, in ooreenstemming met die meeste nuwere kommentare, beskou Ps. 20 en 21 as twee by mekaar behorende gebede, respektiewelik voor en na die slag ( $s i e n$ bv. KitTel, Die Psalmen, 19223, ${ }^{4}$, BöHL, De Psalmen, 1946). Maar reeds Delirzsch het opgemerk, hoewel hy in wese dieselfde beskouing bied, dat ook Ps. 21 midden in die oorlog staan (The Psalms, 1887, I, p. 366).

$\mathrm{Na}$ ons mening bring Ps. 20 ons vrywel in dieselfde situasie as Ps. 2. Ook hier het ons te doen met 'n lied wat gesing is ter geleentheid van die troonsbestyging van 'n nuwe koning: netsoos in Ps. 2 het die onderworpe volke van die geleentheid gebruik gemaak om die juk van die dinastie af te werp. Die koning verkeer daarom juis aan die begin van sy heerskappy in groot gevaar en het dan meer as ooit die hulp van sy God nodig.

Anders as in Ps. 2 word hier uitdruklik melding gemaak van die offers wat die koning bring. Daarop volg die bekende en raaiselagtige sèla. As dit inderdaad, volgens die oudste en beste verklaring, 'n tussenspel sonder sang aandui, dan sou dit die regte oomblik wees vir die koning om sy bede te formuleer en vir die Godheid om met 'n 
belofte te antwoord. Mens vra hom af of GREgorius van NySSa met sy definisie van sèla as ,'n stilte wat in die gemeente midde tussen die psalmgesang plaasvind tot ontvangs van die van God se kant beskikte gedagte" nog iets geweet het van die moontlikheid dat sèla die stilte vir die godsopenbaring gebied. Daar is egter baie plekke waar hierdie betekenis van sèla minder paslik lyk.

In ieder geval, die teks van die psalm gaan vervolgens voort met die woorde: "Mag $\mathrm{Hy}$ u gee na u hart en al u voornemens vervul." As ondertussen die orakel van die Godheid gegee is, kan ons hier beter pleks van ' $n$ wens 'n sekerheid in ons vertaling aandui : „Hy sal u gee na u hart, en al u voornemens vervul." In ieder geval word hier gesinspeel op 'n wens, wat die koning in sy hart koester. Dat daardie wens ook uitgespreek is, tot 'n bede geword het, blyk uit die slot van die volgende vers: ,Mag die HERE al u begeertes vervul!" Die Hebreeuse woord vir "begeertes" kom van dieselfde stam as die werkwoord sjä'al en beteken dus nie 'n wens wat in die hart verberg gehou is nie, maar een wat openlik uitgespreek is, 'n bede. Die Septuaginta het hier dieselfde woord as in I Kon. 3:5 Hierdie sin veronderstel dus dat die koning tevore sy bede uitgespreek het. Merkwaardig is wel, dat nes in Ps. 2 ook hier die sinspeling op die "bede" uit die gewone metrum uitval.

Die inhoud van die bede kan ons aflei uit die res van die psaln: die oorwinning op die vyande wat roem "op strydwaens en perde": dit is dus verwant aan wat ons as inhoud van die bede by Ps. 2 gevind het.

Ook in die volgende psalm, wat nou met die voorafgaande verwant is, vind ons ' $n$ spoor van die koningsbede. Dat ook hierdie psalm 'n lied by die troonsbestyging is, het BöHL in sy kommentaar uiteengeset. Hy dink egter aan 'n ,hernieuwde troonsbeklimming" van die koning en oordeel dat ons psalm "niet slechts een overwinningslied naar aanleiding van een gelukkigen veldtocht" is, maar ook spreek van "de vreugde over het heil, dat God naar aanleiding van de hernieuwde troonsbeklimming zal schenken en reeds heeft geschonken." Daardie hernuwde troonsbestyging sou die jaarlikse oorwinning op die magte van die duisternis wees, wat die koning by die herfsfees as verteenwoordiger van die godheid behaal en uitbeeld.

Ons dink egter, dat ons beter hier aan die eerste en eintlike troonsbeklimming kan dink. Daarop wys veral die feit, dat hier, in Ps. $21: 3$, opnuut gespreek word van „die wens van sy hart". Weliswaar word hier 'n ander woord gebruik (ta'awa), maar daardie verlange is uitgespreek, soos blyk uit ,die begeerte van sy lippe”, en uit vers 5: „Die lewe het hy van $U$ begeer." 
Hier het ons dan 'n koningsbede, wat ooreenstem met een van die moontlikhede, wat in I Kon. 3:11 opgesom word; en nog wel die eerste: ' $n$ lang lewe. Want dat dit die bedoeling is blyk uit die vervolg van Ps. 21:5: „U het hom dit gegee: lengte van dae, vir ewig en altyd." Egter tref ons hier iets aan, wat min of meer herinner aan die geskiedenis van Salomo: soos Salomo meer gekry het as net die wysheid, namelik ook rykdom en eer (I Kon. 3:13), so roem ook die psalm op meer gawes : eer, majesteit en heerlikheid (vs. 6), vgl. I Kron. 29:25; vreugde (vs. 7), vgl. Ps. $45: 8$; en natuurlik ook die dood van die vyande (vs. 9-13), vgl. Ps. 2 en 20.

Daar is dus geen rede, om aan te neem dat hierdie psalm gesing is na die oorwinning op die oproerige volke of na die onderwerping van die magte van die duisternis nie; die hele psalm is 'n danklied nadat deur die Godspraak bekend gemaak is dat die Godheid die koningsbede by sy troonsbesklimming verhoor het. Alleen op hierdie manier kan verstaan word, dat die psalm 'n danktoon aanhef, terwyl tog blykens vs. 9-13 die stryd nog aanstaande is. Die Godspraak, die Woord van die Here, is op sigself genoeg om dankbaar vir te wees. So kry ons hier plotseling een van die grondgedagtes van die reformatoriese teologie!

Die laaste voorbeeld wat ons sal gee is heelwat minder duidelik: Ps. $27: 4$. Dis die bekende woorde: ,Een ding het ek van die HERE begeer, dit sal ek soek; dat ek al die dae van my lewe mag woon in die huis van die HERE, om die lieflikheid van die HERE te anskou en te ondersoek in sy tempel." BöHL neem aan, dat hier die koning self aan die woord is, en daarop wys tog ook wel die vermelding van vyande, laer en oorlog, wat nie als beeldspraak hoef opgevat te word nie. In dieselfde rigting wys ook die (dank)offers met gejubbel, waarvan vs. 6 in verband met die oorwinning op die vyande spreek.

Merkwaardig is in hierdie verband die saak, wat die koning "begeer" het (opnuut 'n vorm van sjä'al, dus liewerste ",gebid", "gevra"): 'n voortdurende verblyf in die tempel. Dit sou die leser die eerste oomblik kan laat dink, dat hier 'n priester aan die woord was; maar die koning was in Jerusalem tegelyk opperpriester, en dieselfde bede kom as koningsbede ook voor in Ps. 61:5, wat miskien, vergelyk die bede om ' $n$ lang lewe in vs. 7 van dieselfde psalm, ook tot die groep van die koningsbede by die kroningsritueel gereken moet word. Selfs sou mens kan dink aan Ps. 84, waar vs. 10 'n bede vir die koning vorm en vs. 11 'n bidder, vermoedelik die koning self, sy verlange uitspreek om steeds in die heiligdom te mag verkeer. Daar egter nog in Ps. 61, nòg in Ps. 84 die werkwoord sjăal voorkom, kan hulle nie met stelligheid tot dieselfde groep as 2, 20, 21 en 27 gereken word nie.

Netsomin wil ons ingaan op die feit, dat in Ps. 37:4 gespreek word van .,die begeertes van jou hart." Dis moontlik, aangesien ons 
hier weer met ' $n$ vorm van die stam $s j a a^{\prime} a l$ te doen het, dat hier 'n formule uit die kroningsritueel bewaar gebly het, maar verder is daar niks in die psalm wat op verband met die koningsbede wys, en baie wat daarteen pleit. Ook Spr. 30:7 het niks met ons onderwerp van doen nie; 'n koning sal nie vir armoede bevrees wees nie.

$\mathrm{Al}$ is ons aantal voorbeelde nie so talryk nie - afgesien van ons uitgangspunt, Salomo se geskiedenis, het ons vier vermeldings van die koningsbede in die psalms gevind - dit is tog wel voldoende om die bestaan van ' $n$ koningsbede as vaste element by die kroningsplegtighede te erken.

Die vraag kom op, of ons hier met 'n spesifiek-Israelitiese rite te doen het dan wel met 'n gebruik wat ook by ander voor-Asiatiese volke bekend was.

'n Direkte parallel het die skrywer van hierdie opstel nog nie kan ontdek nie. In die literatuur van Ras Sjamra is die werkwoord $s j \bar{a}^{\prime}$ al baie skaars; tot nou toe is dit net aangetref in die nogal fragmentariese brief RS 18, waar dit drie maal voorkom maar seker nie in verband met 'n koningsbede nie. In die Amarna-literatuur ontbreek die parallelle ook; die digste by ons tekste kom nog die seënwens van koning Tusjratta aan Farao Amenhotep III : „Mag Istar, die heerseres van die hemel, my broer en my beskerm! Mag daardie meesteres honderdduisend jare en groot vreugde aan ons altwee skenk!" (ed. KundTZON no. 23, 26-29.) Die ooreenkoms met die bedes van Ps. $21: 5$ en 7 is treffend, maar hierdie seënbede is nie by die troonsbestyging van Amenhotep uitgespreek nie, dog op 'n oomblik dat hy al nie ver meer van die dood af was nie, soos blyk uit die aantekening van die Egiptiese argivaris, wat die ontvangs in die 36ste jaar van die koning (sy sterfjaar) dateer.

Deur E. F. WeidNer is in ' $n$ artikel oor .. Assurbanipal in Assur" in Archiv für Orientforschung, 1940, p. 204-218 'n teks gepubliseer, wat volgens E. EBELING (ibid. p. 324) 'n kroningshimne is, deur die priesters gedig by die geleentheid van die troonsbeklimming van die koning. In hierdie teks (VAT 13831) word die koning toegebid, dat hy van die gode as geskenk mag ontvang ,bevel en gehoorsaamheid, reg en billikheid" (vgl. die bede van Salomo volgens Kon.); goedkoopte van die noodsaaklikste lewensbehoeftes; eendrag en vrede; lewensbeskerming en lewensverlenging (vgl. Ps. $21: 5$ ); liggaamlike en geestelike welbehae, vreugde van die hart (Ps. 21:7); die eerste rang onder die konings, en die vernietiging van die opstandiges en verraaiers (Ps. 21 : 9-13).

Die enigste wat in hierdie teks ontbreek om dit tot 'n volkome parallel van ons tekste te maak is die uitnodiging van die kant van die godheid: .Vra!" Dit is natuurlik moontlik dat dit inderdaad aan 
die gebed, wat WEIDNER se teks weergee, voorafgegaan het, maar aangesien in die teks die priester en nie die godheid aan die woord is, lyk dit of die Assiriese ritueel nie die regstreekse dialoog tussen godheid en koning geken het nie. Dit is egter die mees kenmerkende deel van die koningsbede; die dinge wat 'n koning vra is deur die omstandighede bepaal, en ooreenkomste in daardie opsig hoef nog nie op 'n samehang te wys nie.

Voorlopig moet ons dus wel tot die konklusie kom dat die dialoog tussen godheid en koning, beginnende met die uitnodiging "vra!" 'n spesifiek Israelitiese verskynsel is. By die konings oor Israel wat aan Salomo voorafgaan merk ons niks van hierdie aard op nie; dit bewys natuurlik nie dat die ritueel aan Saul of Dawid onbekend was nie, maar gesien die belangrike hervorming en uitbreiding van die kultus, wat gedurende die tweede helfte van die regering van Dawid plaasyevind het, kan ons aanneem dat inderdaad Salomo die eerste koning was wat in hierdie rituele dialoog opgetree het.

Die rol van die Godheid sal gewoonlik wel deur een van die priesters van die heiligdom waargeneem wees. Daarin het ons dus opnuut ' $n$ voorbeeld van die priester as profeet, of wel van die profeet as een van die priesters wat in 'n amptelike funksie aan die heiligdom verbind was. S. Mowinckel (Psalmenstudien III, Kultprofetie im Psalter, 1923) noem op p. 23 as 'n voorbeeld daarvan ook I Kon. 3:5, maar het die samehang met die deur ons behandelde psalmtekste nie vermeld nie; p. 73-75 kenskets ook hy Ps. 20 en 21 as liturgieë respektiewelik voor en na die krygstog. En ook die laaste monografie oor hierdie onderwerp, A. R. JoHnson, The cultic prophet in ancient Israel, 1944. gaan stilswyend aan die koningsbede in die kroningsritueel voorby. Dit was 'n genoeë vir die skrywer van hierdie verhandeling om 'n klein aanvulling te kan gee op die leerryke studies van die twee genoemde geleerdes.

Pretoria, 29 Maart 1948.

A. van Selms. 